\title{
O(A) INTELECTUAL EM TEMPOS DE INTERNET: A ÉTICA DO(A) TRABALHADOR(A) ONLINE ${ }^{*}$
}

\author{
The intellectual on internet times: the ethic of the online worker
}

\author{
El(la) intelectual en tiempos de la internet: la ética del (de la) \\ trabajador(a) online
}

RESUMo Intelectualidade administrada, intensificação do trabalho docente, adoecimento docente e a semiformação da produção intelectual são algumas das reflexões a serem abordadas neste ensaio em relação aos possíveis redimensionamentos na organização social do trabalho docente de carreira superior, sobretudo em tempos de globalização da internet e de ferramentas tecnológicas de trabalho, como: E-mail, WhatsApp e Facebook - que permitem e impõem a conexão dos docentes em tempo integral. Estamos diante de um novo tipo de trabalhador(a): o(a) intelectual online. Neste ensaio, produzimos alguns conceitos para refletirmos a respeito da semiformação do produtivismo acadêmico fundamentado em uma espécie de mentalidade do ticket "às avessas" e a produção do que optamos por nomear de "preconceito integrativo". Desse modo, os conceitos elaborados neste ensaio são: "Tempo Stand by", "Pré-atenção induzida", "Hiperatenção fluida", "Intelectual online", "(Auto)imagem como autoria" e "Preconceito integrativo".

Palavras-Chave: INTElectual online. Tempo stand by. PrÉ-ATENÇÃO INDUZIDA. HIPERATENÇÃO FLUIDA. (AUTO)IMAGEM COMO AUTORIA. PRECONCEITO INTEGRATIVO.

ABSTRACT Managed intellectuality, intensification of teaching work, teacher illness and the halbbildung of intellectual production are some of the reflexions to be addressed in this essay in relation to possible resizing in the social organization of the higher education teaching work career, especially, in times of internet globalization and technological work tools, such as: E-mail, What sApp and Facebook - that allows and imposes the teachers connection full time. We are in front of a new type of worker: the online intellectual. In this essay, we produce some concepts to reflect on the academic halbbildung productivism based on a sort of "backward ticket mentality" and the production of what we chose to name as integrative prejudice. Thus, the concepts elaborated in this essay are: "Stand by Time", "Induced pre-attention", "Fluid hyperattention", "Online intellectual", "(Self)image as authorship" and "Integrative prejudice".

KEY-WORDS: ONLINE INTELLECTUAL. STAND BY TIME. INDUCED PREATTENTION. FLUID HYPERATTENTION. (SELF)IMAGE AS AUTHORSHIP. INTEGRATIVE PREJUDICE.
Isabella Fernanda Ferreira ${ }^{\mathrm{I}}$ I Universidade Federal de Mato Grosso do Sul (UFMS/CPAN), Corumbá/MS - Brasil.

* O ensaio intitulado "O(a) intelectual em tempos de internet: a ética do trabalhador(a) online" traz reflexões teórico-críticas decorrentes do fragmento "Sabedoria e vulgaridade intelectual: um divórcio certo" escrito e lido pela professora Dra. Isabella Fernanda Ferreira, na mesa de abertura do II Simpósio Internacional de Teoria Crítica e I Encontro Nexos: Teoria Crítica e Pesquisa Interdisciplinar: "As vicissitudes da experiência no mundo digital".

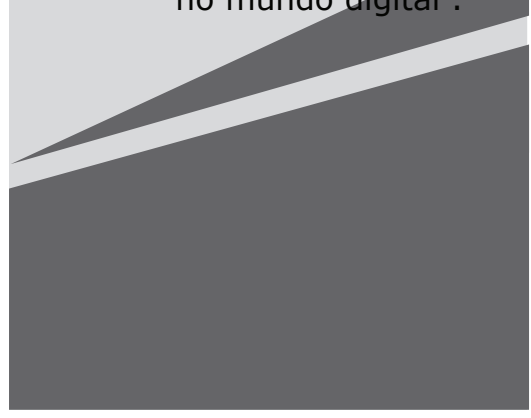


RESUMEN Administración de la intelectualidad, intensificación del trabajo docente, enfermedad docente y el halbbildung de la producción intelectual son algunas de las reflexiones a ser enfocadas en este ensayo a respecto de los posibles redimencionamentos de la organización social del trabajo docente de carrera superior, especialmente, en tiempos de globalización de la internet y de las herramientas tecnológicas de trabajo, como: Correo electrónico, WhatsApp y Facebook - que permite e impone la conexión de los docentes en tempo Integral. Estamos frente a un nuevo tipo de trabajador (a): el (la) intelectual online. En este ensayo, elaboramos algunos conceptos para reflexionar sobre la halbbildung del productivismo académico fundamentado en una especie de "mentalidad ticket al revés" y la Producción de lo que elegimos llamarlo de "prejuicio integrador". De este modo, los conceptos elaborados en este ensayo son: "Tiempo de Stand by", "Atención pre-inducida”, “Hiperatención fluida”, "Intelectual online", "(Auto) imagen como autoría” y "Prejuicio integrativo".

PALABRAS CHAVE: INTELECTUAL ONLINE. TIEMPO DE STAND BY. PRE-ATENCIÓN INDUCIDA. HIPERATENCIÓN FLUIDA. (AUTO)IMAGEN COMO AUTORÍA. PREJUICIO INTEGRATIVO.

\section{SABEDORIA E VULGARIDADE}

\section{INTELECTUAL: UM DIVÓRCIO CERTO ${ }^{1}$}

O sábio não busca mostrar o número de livros que possui nas pratelei-

\footnotetext{
Dedico esse fragmento às pesquisadoras Doutoras Deborah Christina Antunes, Marilia Mello Pisani, Roselaine Ripa, Rosi Giordano e a todos que compõem a nossa Rede de Pesquisa "NEXOS Teoria Crítica e Pesquisa Interdisciplinar", bem como, a nossos parceiros - pesquisadores brasileiros e estrangeiros. Tal fragmento recitado e dedicado a todos os citados, na ocasião da mesa de abertura do "Il Simpósio Internacional de Teoria Crítica e Pesquisa Interdisciplinar e I Encontro NEXOS Teoria Crítica e Pesquisa Interdisciplinar", simboliza um reconhecimento pelo esforço do trabalho intelectual coletivo desses pesquisadores e pesquisadoras, que vislumbram resistir à lógica mercadológica impregnada no trabalho intelectual dos docentes de carreira superior.
}

ras da sua casa ... ele os lê e mais do que isso ... ele permite que os livros escrevam nele...

O sábio não busca a superficialidade dos números no seu Lattes ... sim, porque sabe, que qualquer menção a números traz em si mesmo um potencial de coisificação do humano ... Ele sabe que a meritocracia é uma falácia e que os números podem estar associados à superficialidade ou à apropriação do alheio... Ele não se deixa corromper por essa lógica!

Seu silêncio ativo é a sua resistência! Sua presença silenciosa é humilhação para a fútil vaidade acadêmica...! Se para os semiformados atuantes nesse espetáculo... as palmas, prêmios, troféus, apresentam-se como uma necessidade vã de autoafirmação de uma vida intelectual ainda muito infantil... para o sábio tudo isso é insípido, inodoro e incolor...! Ele não se ilude com as imagens...! E principalmente, por não estar competindo com ninguém..., por compreender que toda comparação é imperfeita... e que toda vontade de ser "campeão" tem em si mesma uma vulgaridade..., justamente por isso: ninguém, repito, absolutamente ninguém neste mundo... pode competir com ele! É esse, o (a) sábio (a)!!! Isabella Fernanda Ferreira, 2017

O ensaio "O(a) intelectual em tempos de internet: a ética do(a) trabalhador(a) online" objetiva tecer reflexões teórico-críticas acerca de possíveis redimensionamentos que a organização social do trabalho intelectual tem passado, sobretudo, por meio de tecnologias que possibilitam a permanente conexão entre os sujeitos - ainda que separados fisicamente -, com possibilidades de constituírem redes de relações. Destacamos como mediadores tecnológicos dessas relações para a efetivação do trabalho intelectual 
do docente do magistério superior: o e-mail, o Facebook e o WhatsApp.

Como dimensão macrossociológica constitutiva de tais relações sociais digitais entre docentes do ensino superior, sinalizamos como indissociáveis em nossa análise: a lógica mercadológica específica do sistema capitalista na produção do conhecimento e a ética desse(a) trabalhador(a) contemporâneo com o surgimento do que categorizamos como trabalhador(a) online. Uma ética composta de materialidades objetivas e subjetivas que conceituamos como: tempo stand by com a exigência de uma pré-atenção induzida e de uma hiperatenção fluida, a aceleração do tempo para a execução de demandas para a produção, a (auto)imagem como autoria e, por fim, a produção de um preconceito integrativo. São todas essas, categorias analíticas criadas neste ensaio para a reflexão de materialidades objetivas e subjetivas que se apresentam como imperativo para o reconhecimento e permanência na rede de relações que se estabelecem entre os(as) intelectuais e seus pares. A relação entre essas dimensões sociais tem se apresentado como algumas das facetas que constituem o fenômeno do produtivismo acadêmico e, com ele, a possibilidade do adoecimento docente e a queda na qualidade das produções científicas - que pode ser denominada, a partir das contribuições analíticas de Adorno (2010) - de intelectualidade semiformada.

Levando em consideração a tradição marxista presente nas análises teórico-críticas, elencamos o trabalho e suas diferentes formas de organização - com suas dimensões objetivas e subjetivas -, como uma das principais mediações para a compreensão do modo como se constituem as relações sociais no sistema capitalista e, em específico, o modo como se constituem as relações sociais de produção entre os docentes que atuam no ensino superior.

Marcuse (1973) já nos explicitou a presença social de um duplo significado para os processos de racionalização. É possível constatar, no processo de gerência e de divisão científica do trabalho, um aumento significativo da produtividade no que concerne aos empreendimentos econômicos, políticos e culturais, em um contexto social no qual uma sociedade reproduz, por meio de um crescente conjunto técnico, tanto a possibilidade de uma existência mais humanizada como também de um processo de exploração do homem e da natureza. Nesse aspecto, com o progresso técnico e a melhora de um padrão de vida, tem sido produzido também "um padrão de mente e comportamento que justificou e absolveu até mesmo as particularidades mais destrutivas e opressivas do empreendimento" (MARCUSE, 1973 p. 144).

Tal problemática social, já anunciada por Marcuse, em sua obra "A ideologia da sociedade industrial: o homem unidimensional", faz-nos refletir acerca dos padrões de pensamento, assim como os padrões de comportamento que têm sido unidimensionalizados no trabalho intelectual dos docentes que atuam no ensino superior. Trata-se de padrões de pensamento e comportamento que estão indissociáveis do modo como a organização do trabalho desses trabalhadores tem se configurado, dando destaque às mediações realizadas pela tecnologia que, isenta de neutralidade, tem redimensionado tais formas de organização.

\section{O REDIMENSIONAMENTO DA ÉTICA DO(A) TRABALHADOR(A) NA ORGANIZAÇÃO SOCIAL DO SEU TRABALHO}

Sennett (2011) é um dos teóricos que associaram as diferentes formas históricas de organização da produção aos diferentes processos formativos de constituição de éticas para o trabalho. Levando-se em conta esses diferentes processos formativos para éticas distintas, o autor realiza uma tipificação sociológica desses trabalhadores.

Rememorando clássicas obras - inseridas em seus respectivos tempos históricos de produção/criação -, como "Os trabalhos e os dias" de Hesíodo, "Geórgicas" de Virgílio, "Confissões" de Santo Agostinho, bem como, "A ética protestante e o espírito do capitalis- 
mo" de Max Weber, Sennet (2011) apresenta, em sua reflexão, três diferentes tipos de homens. Tal tipologia está diretamente relacionada às diferentes éticas que socialmente são constituídas por uma formação que possui como mediação a própria organização social do trabalho. Podemos afirmar que, em síntese, esses distintos tipos de homens sinalizados por Sennett (2011) seriam:

- O "camponês feudal e/ou cristão católico" - teria a ética do seu trabalho constituída por uma formação que valoriza o que o autor denominou de estoicismo prático. ${ }^{2} \mathrm{~A}$ ética desse tipo de trabalhador teria como objetivo central conquistar a absoluta programação do seu tempo na organização do seu trabalho. Para isso, tal trabalhador tem, na autodisciplina e na organização de rituais programados de comportamento, a possibilidade de poder ser considerado um trabalhador apto na execução de suas atividades laborais.

- O "homo faber e/ou homem motivado", considerado pelo autor como aquele que é o seu próprio criador. Esse tipo de trabalhador também possui uma ética cristã, entretanto, não como a do católico, estamos diante do homem protestante. Em tal ética, o trabalho teria a função social de modelar a história individual, por meio de uma espécie de teleologia do indivíduo anunciada por Lutero - introduzindo um trabaIho contínuo e árduo voltado para o futuro -, em forma de ascetismo leigo ${ }^{3}$ que:

O(a) leitor(a) pode encontrar com maiores detalhes o que significa estoicismo prático para Sennet (2011) nas páginas 120 e 121 da sua obra "A corrosão do caráter" citada nas referências deste ensaio.

3 Apropriando-se do pensamento de Max Weber na obra "A ética protestante e o espírito do capitalismo", Sennett (2011), esclarece o seu entendimento sobre ascetismo leigo nas páginas 122 a 123 da sua obra "A corrosão do caráter” citada nas referências deste ensaio.
[...] oferecia ao protestante, em vez do bálsamo do ritual, um remédio mais amargo: trabalho árduo implacável, voltado para o futuro. A organização da história de nossa vida pelo trabalho árduo pode servir como uma pequena luz na escuridão, um "sinal de eleição", de que podemos estar entre os que serão salvos do inferno. Ao contrário das boas obras católicas, porém, o trabalho árduo não pode conquistar para o protestante nenhum grande favor junto ao Criador; apenas oferece sinais de intenções dignas a um Juiz divino que já decidiu cada caso de antemão.

Esse é o terror que se esconde por trás do conceito abstrato de "ascetismo leigo". Na opinião de Weber, a maior disposição de poupar do que de gastar passou do protestante para o capitalista como um ato de autodisciplina e autonegação. Essa mesma passagem deu origem a um novo tipo de caráter. É o homem motivado, decidido a provar seu valor moral pelo trabalho (SENNETT, 2011, p. 125).

- $\quad$ E, por fim, Sennett (2011) anuncia o que ele tipifica de "homem irônico" - detentor de uma ética de trabalho que se baseia em uma organização em equipe para o desenvolvimento das atividades laborais. Em tal ética, a confirmação individual é substituída por um processo de mútua responsabilidade. Nessa forma de organização do trabalho, o tempo se torna mais flexível e se desenvolve em torno de atividades em grupo e de curto prazo. Outra característica dessa forma de organização do trabalho é a ausência da figura do chefe como sinônimo da personificação da autoridade. Tal ausência é substituída pela função de líder da equipe como organizador 
na distribuição das tarefas, mas que não se responsabiliza pela produção. Os resultados da produção são de total responsabilidade da equipe. Com essa ética fundamentada em um trabalho em equipe, os próprios pares farão vigília sobre o trabalho dos parceiros, pois a improdutividade do colega representa a sua própria improdutividade. Estamos diante, portanto, de outra forma de opressão do trabalhador que é efetivada pelos próprios parceiros.

Embora concordemos com as características sinalizadas por Sennett (2011), quando descreve o "homem irônico", gostaríamos de sinalizar que talvez o termo "irônico" não fosse o mais adequado, uma vez que, filosoficamente, ele remete à possibilidade de crítica. Ramos-de-Oliveira (2004) argumenta em seu texto "A ironia como ato de desvelamento" que a ironia seria um fundamental recurso da Teoria Crítica e do pensamento negativo, em especial, tanto nas análises sobre estética, como nos estudos e ensaios de Theodor W. Adorno. Ainda, enfatiza:

A ironia, na verdade, é uma maneira de expressar oralmente, por escrito ou até por posturas e tiques comportamentais, que há uma violenta contradição entre o que é colocado e o que é verdade. A ironia é um cheque-mate. $O$ que o Outro pensa, sua visão ou sentimento do mundo tornam-se insustentáveis, incoerentes, logicamente contraditórios, revelados, desvelados, postos a nu. Trata-se de um conceito que a língua inglesa chama de "guarda-chuva", isto é que protege, cobre, um amplo espectro de sentidos, mesmo que alguns excludentes de outros. Toda esta mobilidade por quê? Porque os conceitos humanos são complexos e mutáveis como a realidade a que se referem.
[...]. O espírito irônico autêntico implica as expressões de vida que são alegres, brincalhonas, marotas. Como diria Nietzsche, o irônico é equilibrista, é aquele que diz "minha alma dança", Dança onde? Em todos os lugares, mesmo à beira do abismo.

O fanatismo não combina com o espírito irônico. A ironia não diz o que é a verdade ou o que a verdade deve ser: isto a enfraqueceria. A ironia diz o que a verdade não é, o que não deve ser. $\mathrm{E}$, na verdade, não diz: deixa a iniciativa e à percepção do Outro a surpresa, a revelação, o desnudamento. É o pensar negativo, aquele ato que, como no ato de fotografar, precisa do negativo para desnudar a realidade (RAMOS-DE-OLIVEIRA, ${ }^{4}$ 2004, p. 77-78).

Entretanto, de modo geral, concordamos com os posicionamentos de Sennett (2011) e gostaríamos de salientar que o redimensionamento da ética do(a) trabalhador(a) no sistema capitalista de produção está imanentemente associada a como esses trabaIhadores se organizam para executar as suas atividades laborais. Esse redimensionamento é produzido, sobretudo, pelo modo como os(as) trabalhadores(as) se relacionam com as tecnologias disponíveis para o desempenho de suas atividades. Uma forma de se relacionar com as tecnologias disponíveis para o seu trabalho, que podem terminar por se configurar em um mundo naturalizado e, portanto, não historicizado - o que, nos termos de Marcuse (1973), podemos conceber como uma espécie de entendimento sobre o mundo que se petrifica e

4 Notas sobre o autor Newton Ramos-de-Oliveira: gostaria de registrar que além de exímio pesquisador em Teoria Crítica também foi em vida um exímio irônico crítico. Neste sentido, deixo uma singela homenagem, ao afirmar que se trata de um pesquisador que em sua produção intelectual resistiu à lógica semiformativa denunciada neste ensaio. Recordo-me de suas palavras: um bom leitor sempre está atento às notas de rodapé, pois, por vezes, nelas podem estar contidas os aspectos mais importantes de um texto - desse modo, concordando com o mencionado autor e como autora do presente ensaio, considero apropriada esta rica observação em uma nota de rodapé. 
se apresenta como unidimensionalizado. Algo semelhante é demonstrado, nos termos de Adorno (2010), como manifestações de uma mentalidade que se mostra etiquetada, imobilizada para elaborar julgamentos, tanto em termos objetivos como em termos subjetivos, a respeito do que lhe é imposto como uma espécie de segunda natureza.

$\mathrm{Na}$ contemporaneidade, sobretudo, com o avanço da internet e seu processo social de globalização, estamos presenciando um redimensionamento da ética do trabalho e, com ela, as formas de organização do processo produtivo. Características como a percepção acelerada do tempo, o rompimento total da distinção entre tempo livre e tempo para as atividades laborais, bem como, da não distinção entre local e não local destinado ao trabalho, são alguns dos elementos que constituem a base formativa da ética do trabalhador contemporâneo que aqui optamos por denominar de "trabalhador(a) online" e/ou o que podemos considerar o homem que possui como ética de seu trabalho o imperativo da conectividade em tempo integral, ou seja, uma ética autoritária que nega o direito ao trabalhador de estar indisponível, inacessível, ausente, enfim, desconectado. Tal imperativo só é possível de se estabelecer como normatividade organizacional no trabalho, por meio da internet com suas diferentes possibilidades de conexão virtual.

\section{O AUTORITARISMO CONTEMPORÂNEO DA DISPONIBILIDADE IMEDIATA E A ÉTICA DO(A) TRABALHADOR(A) ONLINE}

Em diferentes tempos históricos, as tecnologias se apresentam como elemento central de mediação entre o ser humano e o seu trabalho e, para além disso, como constituidoras das éticas desses(as) trabalhadores(as). Na contemporaneidade, essa também é uma realidade que precisa ser refletida em termos filosóficos e sociológicos. Concordamos com Marcuse (1973), que as tecnologias possuem em si mesmas um a priori político que, em tempos de uma cultura com a presença do digital, configura a experiência de uma nova éti- ca que se apresenta como formativa para o(a) trabalhador(a) contemporâneo. Entre os(as) diferentes trabalhadores(as) que compõem a organização social do trabalho no sistema capitalista de produção, daremos especial enfoque aos docentes da carreira do magistério superior, com destaque para uma de suas responsabilidades sociais que se encontra na tarefa de produzir conhecimento, enfim, de realizar pesquisas.

Um dos fenômenos sociais que têm se estabelecido por meio do processo de globalização da internet e seus suportes interativos, dos quais podemos citar o e-mail, WhatsApp e o Facebook, é o encurtamento do tempo disponível para a execução do trabalho ou ainda o que poderíamos também denominar de uma percepção acelerada do tempo - um tempo que deixa de ser mediado e passa a se estabelecer como imediato, no que concerne às demandas laborais - estamos, portanto, diante de uma nova experiência com relação ao tempo. Com a percepção acelerada do tempo, coloca-se ao(à) trabalhador(a) o imperativo da conectividade em tempo integral, na tentativa de responder de maneira instantânea e imediata às demandas que o trabalho lhes impõem - nessa ética do(a) trabalhador(a) online quanto mais rápidas e instantâneas forem as suas respostas, tanto mais eficiente ele(a) será considerado pelos seus pares, pois, trata-se de uma ética que não se estabelece de maneira hierárquica, mas sim de um autoritarismo que se manifesta entre os próprios pares.

Uma tentativa de resistência objetiva aos malefícios causados aos(às) trabalhadores(as) pela imposição dessa ética da conectividade em tempo integral, consolidou-se em forma de uma lei trabalhista na França, que passou a entrar em vigor a partir do dia $1^{\circ}$. de janeiro de 2017. Tal lei foi apelidada de "direito de se desconectar".

Sobre a lei já citada, a notícia da BBC, publicada no dia 2 de janeiro de $2017,{ }^{5}$ co-

\footnotetext{
Notícia do dia 2 de janeiro de 2017 disponível em: $<$ http:// www.bbc.com/portuguese/internacional-38471356>. Acesso em 18 mar. 2017.
} 
loca que empresas que possuam mais de cinquenta funcionários serão obrigadas a elaborar uma carta sobre boa conduta, na qual expõem-se os horários em que os(as) trabalhadores(as) não devem enviar e-mails nem responde-los. A lei, ainda, oferece o direito do(a) trabalhador(a) ignorar mensagens de celular.

A notícia da BBC ainda esclarece que, segundo os defensores da lei, os(as) trabalhadores(as) não estariam recebendo o pagamento justo de horas extras, e ainda que tal prática pode ser fator de risco para o desenvolvimento da Síndrome de Burnout ${ }^{6}-$ esgotamento tanto físico como mental dos sujeitos -, assim como pode se tornar causa de dificuldade para relacionamentos interpessoais e de dificuldades do sono. Na notícia, cita-se a fala do parlamentar socialista Benoite Haman feita à $B B C$, em que ele afirma que "Os funcionários saem do escritório, mas não deixam o trabalho em si. Eles são mantidos presos em uma espécie de coleira digital, formada por mensagens de celular e e-mails. Assim, as empresas invadem a vida da pessoa, a ponto que ela acaba surtando".?

Em outra notícia, também publicada no dia 2 de janeiro de 2017 pela Euronews, ${ }^{8}$ relata-se que a medida teria sido criada com a finalidade de proteger tanto a saúde como a vida privada dos funcionários. A preocupação tanto de ministros como dos sindicatos franceses, fundamenta-se na possibilidade de que os(as) trabalhadores(as) não estejam sendo respeitados quanto à carga horária de 35 horas semanais de trabalho que vigora no país, bem como, a negação do lazer e do descanso.

Essa lei, como dado empírico, revela-nos que a definição de virtual como isenta

6 Notas sobre a definição do que é Burnout e suas características são possíveis de serem encontradas nas páginas 23 e 24 do texto "A síndrome de Burnout e o trabalho docente" de Carlotto (2002) citado nas referências deste ensaio.

7 Citação disponível em: <http://www.bbc.com/ portuguese/internacional-38471356>. Acesso em: 18 mar. 2017.

8 Notícia de 2 de janeiro de 2017 disponível em: <http:/l pt.euronews.com/2017/01/02/franca-introduz-direitode-ignorar-emails-fora-do-trabalho $>$. Acesso em 18 mar. 2017. de materialidade precisa ser analisada, pois o virtual é constituído de materialidades, tanto objetivas como subjetivas, que compõem e interferem na organização da vida dos seus usuários. Nesse aspecto, conceitos como ciberespaço (LÉVY, 1996) e cibercultura (LÉVY, 1999), como também todos aqueles que possuem a tendência sociológica a separar a experiência virtual das demais experiências a que os sujeitos estabelecem na rotina das suas vidas, precisam ser revitalizados. Considerar a existência de uma cibercultura como sendo uma cultura produzida e específica do ciberespaço é dissociá-la das demais instâncias que compõem a vida dos sujeitos, e mais, é desconsiderar as materialidades que o uso de tais tecnologias produzem ou redimensionam, transformando-as. Portanto, realidades como o estar na internet com status on-line, com status definido como off-line ou, ainda, desconectado da internet são diferentes facetas de um mesmo universo cultural que se configura mediante essas múltiplas relações.

As relações entre essas diferentes realidades produzem materialidades tanto objetivas como subjetivas na vida dos sujeitos. No que concerne especificamente à organização social do trabalho dos docentes universitários, em especial atenção às atividades laborais relacionadas ao desenvolvimento de pesquisas, podemos refletir sobre algumas das características que compõem a ética desse trabalhador(a) online e, no que diz respeito especificamente aos docentes que atuam no ensino superior - a ética do(a) intelectual online. Nesse contexto social, e em decorrência do dado empírico explicitado, gostaríamos de refletir acerca de algumas materialidades que configuram no sistema capitalista contemporâneo de produção o trabalho do(a) intelectual online ${ }^{9}$ no Brasil.

\footnotetext{
9 A partir desse momento do ensaio, utilizamos o conceito de "intelectual online" como maneira de especificar um trabalhador(a) - os(as) docentes do ensino superior e suas atividades laborais de pesquisa junto aos programas de pós-graduação -, como sendo uma das variáveis do que denominamos de trabalhador(a) online.
} 


\section{MATERIALIDADES DO(A) INTELECTUAL ONLINE: AS METAMORFOSES DO TEMPO, DA ATENÇÃO E DA AUTORIA}

A ética no trabalho do(a) intelectual online, trata-se daquela que se é produzida em um contexto social de processos de globalização cada vez mais intensificados, sobretudo, por meio da internet e da sua tecnologia interativa. As fronteiras físicas para as interações sociais são cada vez mais diminuídas, ao mesmo tempo em que são intensificadas. Essa ética contemporânea do(a) intelectual online, levando em consideração as análises já realizadas pelos estudos de Adorno, pode ser compreendida por ter, como elemento imanente, uma socialização que busca constantemente a integração, ou seja, uma ética constituída e constituinte de uma sociedade que tem se tornado, cada vez mais, integrada. Nesse contexto social,

[...] a socialização total, como historicamente a conhecemos, opera metódica e sistematicamente a liquidação do indivíduo e de toda singularidade, por meio de sua integração sem resíduos na anônima generalidade dos grupos coletivos de interesses e nas categorias de estratificação social. Por outro lado, a sociedade absolutamente administrada é também a forma de estruturação das relações econômicas, sociais, e políticas em que aparece se realizar historicamente o ideal filosófico de constituição de uma ordem social inteiramente fundada na racionalidade, tendo por suporte a objetivação científico-tecnológica da natureza, a exploração e o aproveitamento de seus recursos para fins da promoção do bem-estar da humanidade e a possibilidade de resolução racional dos conflitos de interesses particulares. [...]. Quanto às questões éticas suscitadas no campo minado das tensas relações entre ordem social e liberdade individual ou de grupos particulares, seu tratamento adequado constituiria objeto das ciências sociais e políticas e, no limite extremo, encontrariam solução no âmbito das tecnologias de controle social. Qualquer universalismo éti$\mathrm{co}$, no interior do qual ainda se suscitassem questões acerca da justiça e do valor moral das ações, se refugiaria, em última instância, no quadro transcendental de regras meramente formais de comunicação, de que estaria banido, por princípio, qualquer conteúdo ético vinculante. Por conseguinte, a ética na era da globalização implicaria o risco de uma dupla perda: por um lado, o desaparecimento da individualidade, e, por outro lado, a dissolução do domínio de legitimidade da reflexão filosófica (GIACOIA JUNIOR, 2001, p. 68-69).

Nesse sentido, a ética produzida simultaneamente pelo e no sistema capitalista globalizado de produção está presente em todos os "lugares", seja esse "local" virtual e, portanto, não físico (off-line e on-line), ou não. Trata-se de "locais" que se inter-relacionam, e com isso produzem e reproduzem materialidades - sejam essas de característica objetiva e/ ou subjetiva. Tais materialidades se apresentam de inúmeras maneiras na organização social do trabalho, na qual a exigência pela conexão com a internet em tempo integral tem se manifestado como uma tendência em inúmeras profissões. A exigência pela conectividade em tempo integral é o que consideramos um dos fundamentos que edificam a ética do que nomeamos de intelectual online.

Uma das contribuições teóricas de Adorno ao pensamento marxiano do próprio Marx se encontra em sua denúncia ao que ele denominou de processo social de integração ideológica entre as diferentes classes sociais. Tal processo subjetivo de integração ideológica das consciências pelos mecanismos semifor- 
mativos do mercado, principalmente no que diz respeito ao consumo, manifesta-se como um véu que encobre/oculta a cisão entre as diferentes classes sociais. Entretanto, Adorno, também enfatiza que tal integração, por ser ideológica, também possui a sua fragilidade:

O modelo da semiformação, todavia, caracteriza hoje a camada dos empregados médios, ficando claro que seria tão impossível especificar univocamente tanto seus mecanismos nas camadas propriamente baixas quanto a consciência nivelada tomada de modo global. Medida na situação aqui e agora, a asserção da universalidade da semiformação é indiferenciada e exagerada. Não poderia subsumir, em absoluto, todos os homens e todas as camadas indiscriminadamente sob aquele conceito, mas delineia uma tendência, esboça a fisionomia de um espírito que também determinaria a marca da época se tivéssemos de restringir quantitativa e qualitativamente o âmbito de sua validade. É possível que inúmeros trabalhadores, pequenos empregados e outros grupos, graças à sua consciência de classe ainda viva, embora debilitada, não caiam nas malhas da semiformação. Porém, estas são tão fortes com base na produção, seu estabelecimento está tão de acordo com os interesses decisivos e acomodam-se tanto às manifestações culturais atuais, que sua representatividade se impõe, mesmo sem a chancela da estatística (ADORNO, 2010, p. 18).

Como uma tendência que se manifesta em todas as classes sociais e, com isso, nas diferentes profissões, a semiformação é um fenômeno social que também está presente como realidade a ser resistida pelos docentes de universidades públicas que não são imunes a ela, ainda que esclarecidos racionalmente dessa problemática pela qual passa a formação cultural seduzida pelo fetichismo da mercadoria. Diante da problemática da semiformação como uma tendência social, consideramos que a mesma também se configura como presente nos fundamentos que estabelecem a organização social do trabalho e, com ela, a ética do(a) intelectual online.

Especificamente, na organização social do trabalho dos docentes que atuam no ensino superior, na qual uma das suas atribuições é a produção de conhecimento por meio de pesquisas que são efetivadas geralmente junto a programas de pós-graduação, gostaríamos de elencar algumas manifestações que decorrem, ao mesmo tempo em que produzem, o imperativo categórico da disponibilidade em tempo integral do intelectual online. Tais manifestações, como materialidades objetivas e subjetivas, optamos por conceituar de: intelectual online, tempo stand by, pré-atenção induzida, hiperatenção fluida, (auto)imagem como autoria e preconceito integrativo.

\section{O TEMPO STAND BY E O TEMPO LIVRE: A ÉTICA DO(A) INTELECTUAL ONLINE E A MENTALIDADE DO TICKET ÀS AVESSAS - 0 PRECONCEITO INTEGRATIVO}
Verídicos Diálogos Elucidativos: “di- álogo” sobre um orientando.
Cenário: um evento científico.
Sujeito I: Estou pensando em con- versar com um dos meus orientan- dos para ele solicitar prorrogação de prazo para a defesa porque (...)! Sujeito II: Você está louca! Não se pede para orientando pedir prorro- gação de prazo! Tem que fazer no prazo!
Sujeito I: (...)!
Isabella Fernanda Ferreira, 2017

Em virtude da exigência da disponibilidade em tempo integral possibilitada pelas 
ferramentas disponibilizadas e acessadas pela internet, duas problemáticas que intensificam o trabalho docente, e com elas a precarização da qualidade do seu trabalho, têm sido materializadas: a absoluta extensão do local destinado às atividades laborais para os locais destinados a vivências distintas daquelas do trabalho, como também, um aceleramento tanto da percepção do tempo desses trabalhadores(as) como dos prazos atribuídos a esses profissionais para a execução das inúmeras atividades que compõem a sua jornada de trabalho.

Adorno (1995) em seu texto "Tempo livre" traz algumas reflexões importantes para serem levadas em consideração, como também para serem revitalizadas mediante as configurações contemporâneas e o uso das tecnologias da internet no que concerne à organização social do trabalho. Nesse texto, a categoria de análise sociológica "tempo livre" está imanentemente relacionada à produção, distribuição e consumo de mercadorias no sistema capitalista, o que implica compreender que o tempo para não trabalhar e, portanto, considerado "livre", teria como uma de suas centrais finalidades restaurar as forças para o trabalho. Nesse aspecto, o tempo para não trabalhar, bem como, para o lazer, seriam uma pretensa antítese do trabalho que se efetiva somente em termos ideológicos, pois no tempo do não trabalho está contida a racionalidade irracional do trabalho específica do sistema capitalista de produção:

Quando se aceita como verdadeiro o pensamento de Marx, de que na sociedade burguesa a força de trabalho tornou-se mercadoria e, por isso, o trabalho foi coisificado, então a palavra "hobby" conduz ao paradoxo de que aquele estado, que se entende como o contrário de coisificação, como reserva de vida imediata em um sistema total completamente mediado, é, por sua vez, coisificado da mesma maneira que a rígida delimitação entre trabalho e tempo livre. Neste, prolongam-se as formas de vida social organizada segundo o regime do lucro.

[...]. Como, segundo a moral do trabalho vigente, o tempo em que se está livre do trabalho tem por função restaurar a força de trabalho, o tempo livre do trabalho - precisamente porque é um mero apêndice do trabalho - vem a ser separado deste com zelo puritano. Aqui nos deparamos com um esquema de conduta de caráter burguês. Por um lado, deve-se estar concentrado no trabalho, não se distrair, não cometer disparates; sobre essa base, repousou outrora o trabalho assalariado, e suas normas foram interiorizadas. Por outro lado, deve o tempo livre provavelmente para que depois se possa trabalhar meIhor, não lembrar em nada o trabaIho. [...]. Toda mescla, aliás, toda falta de distinção nítida, inequívoca, torna-se suspeita ao espírito dominante. Essa rígida divisão da vida em duas metades enaltece a coisificação que entrementes subjugou quase completamente o tempo livre (ADORNO, 1995, p. 72-3).

As contribuições do pensamento de Adorno (1995) são indispensáveis para compreendermos que a lógica da coisificação, presente na organização social do trabalho específica do sistema capitalista de produção, também é expandida para os momentos que estariam destinados à ausência de trabalho, a qual ele conceitua de "tempo livre" e que é, sem dúvida, ainda presente e pertinente ao tratarmos de fenômenos contemporâneos.

A denúncia realizada por Adorno (1995), de que o tempo no trabalho e o tempo livre, e, portanto, isento dele, seriam duas esferas da vida social que se inter-relacionam alimentando o processo de coisificação em ambos os contextos cotidianos dos sujeitos ? por exem- 
plo, nos momentos destinados ao tempo livre o imperativo que contribui para tal processo se aloja justamente na rígida separação de um tempo que deveria estar relacionado a tudo o que não tivesse relação direta ou indireta com o trabalho, a fim de que o(a) trabalhador(a) se "separasse" totalmente do trabalho como uma espécie de preparo para um retorno mais produtivo - trata-se de um processo de coisificação que se estabelece como integração.

A contribuição do pensamento de Adorno a essa questão está precisamente em demonstrar esse processo de ruptura como uma extensão indireta da lógica existente no processo de produção durante as atividades laborais dos(as) trabalhadores(as). Nesse processo, destaques são sinalizados para os controles sociais suplementares do tempo livre dos sujeitos que são aprisionados pelo caráter fetichista da mercadoria, como também por meio de um estado letárgico de tédio que se configura como uma espécie de desespero objetivo. Nesse sentido, a tendência como integração semiformativa no tempo livre se desenvolve como pseudo-atividade realizada pelo si mesmo sem si mesmo:

O 'Do it yourself', um tipo de comportamento recomendado atualmente para o tempo livre, inscreve-se, não obstante, em um contexto mais amplo. Eu já o designei, há mais de trinta anos atrás, como pseudo-atividade. Desde então, a pseudo-atividade ampliou-se assustadoramente, também $e$ precisamente entre aqueles que se sentem como questionadores da sociedade. De uma forma geral, pode-se presumir, na pseudo-atividade, uma necessidade represada de mudanças nas relações fossilizadas. Pseudo-atividade é espontaneidade mal-orientada. Mal-orientada, mas não por acaso, e sim porque as pessoas pressentem surdamente quão difícil seria para elas mudar o que pesa sobre seus ombros. Preferem deixar-se desviar para atividades aparentes, ilusórias, para satisfações compensatórias institucionalizadas, a tomar consciência de quão obstruída está hoje tal possibilidade. Pseudo-atividades são ficções e paródias daquela produtividade que a sociedade, por um lado, reclama incessantemente e, por outro lado, refreia e não quer muito nos indivíduos. Tempo livre produtivo, não para aquelas que, sob a heteronomia, tornaram-se heterônomas, também para si próprias.

Tempo livre produtivo só seria possível para pessoas emancipadas, entretanto, não está em oposição somente com o trabalho. Em um sistema, no qual, o pleno emprego tornou-se um ideal em si mesmo, o tempo livre segue diretamente o trabalho como sua sombra (ADORNO, 1995, p. 78-79, grifos da autora).

A característica de um tempo livre em que os sujeitos rompem absolutamente com o pensamento no trabalho, ao mesmo tempo em que transportam a lógica mercadológica do trabalho para as suas atividades de "lazer" - um lazer administrado e, portanto, com características coercitivas -, como bem elucidado por Adorno (1995), trata-se de uma realidade também vivenciada por aqueles que se entendem como críticos desse fenômeno social. A essa parcela de críticos da sociedade, dos quais estamos considerando como membros constitutivos os docentes pesquisadores que atuam no ensino superior, esses também não estão isentos de tais processos semiformativos. No que diz respeito ao trabalho desses profissionais, com o advento da internet e com os processos de globalização no mundo do trabalho cada vez mais intensificados pelo desenvolvimento da tecnologia, devemos refletir acerca de um redimensionamento desse processo de coisificação como extensão integrada do trabalho presente no que Adorno denominou de "tempo livre". 
Concordamos que o processo de coisificação como extensão do tempo destinado ao trabalho, existente no modo como se configura, e que Adorno (1995) denominou de "tempo livre", continua a existir como fenômeno social contemporâneo. Entretanto, um redimensionamento nas características da organização do trabalho dos docentes que atuam no ensino superior, faz-nos refletir sobre outra forma de manifestação desse processo de coisificação nos horários que, em tese, estariam destinados ao "não trabaIho", sobretudo, com o advento da internet. Nesse redimensionamento, estamos conceituando o tempo destinado a uma suposta ausência de trabalho de "tempo stand by" e, com ele, também refletimos sobre um redimensionamento no estado de atenção em que esses(as) trabalhadores(as) permanecem submetidos nesse tipo de tempo.

Na obra "Sociedade excitada: filosofia da sensação", de Türcke (2010), a denúncia realizada por esse autor sobre o advento da globalização do uso das tecnologias digitais e a produção da cultura da "distração concentrada" e do "déficit de atenção" é pertinente e verídica na contemporaneidade. Concordamos que a distração concentrada como fenômeno social não pode ser compreendida como exclusividade dos sujeitos portadores de déficits de atenção, mas que se trata de uma das manifestações culturais que dizem respeito às formas como estão sendo materializadas as relações dos sujeitos com as tecnologias digitais e suas inúmeras funcionalidades. No entanto, como tendência social, a problemática da "distração concentrada" e do "déficit de atenção" não pode ser absolutizada como única manifestação semiformativa possível dessas relações.

Para refletirmos a respeito de tais questões, categorizamos o "tempo stand by" como aquele produzido socialmente com o advento da internet e seus aportes tecnológicos interativos - e-mail, Facebook, WhatsApp - que deixam o(a) intelectual online consciente de que ele pode ser acessado a qualquer instante, mesmo não estando em seu local de trabalho. A percepção da possibilidade de ser acessado a qualquer momento para o trabalho causa o que podemos nomear de um estado permanente de espera, de prontidão, de estar presente, ainda que não de maneira física no trabalho, ou seja, uma espécie de pré-atenção induzida que se apresenta numa espécie de estado de atenção em hibernação consciente que pode ser interrompido a qualquer instante.

Realizando uma analogia com a função stand by existente nos dispositivos eletrônicos, esse tempo para o(a) trabalhador(a) seria aquele em que o sujeito é consciente que ele está "desligado" somente temporariamente, mas que continua recebendo energia para que retorne a funcionar de imediato ao ser acessado. Assim como os aparelhos que voltam a funcionar com um simples toque no botão de um controle remoto, o(a) trabalhador(a), encontra-se em um estado de hibernação e vigília que se efetivam ao mesmo tempo. Esse "controle remoto" pode ser compreendido também por analogia como os e-mails, as mensagens inbox no Facebook e pelo WhatsApp, fora do horário e do local de trabalho.

Outra peculiaridade do processo de stand by nos aparelhos eletrônicos é que, mesmo estando desligados por determinado período, eles continuam a consumir energia ou bateria em pequena quantidade. Esse pequeno consumo ininterrupto de energia nos(as) intelectuais é o que estamos conceituando de estado de pré-atenção induzida, advinda do fato de se estar ciente que esse estado pode ser interrompido. Tal percepção é o que não permite um desligar-se completamente do trabalhado, ainda que o(a) trabalhador(a) não esteja sendo acessado. Estamos, portanto, diante de uma organização social do trabalho que em tempo integral está realizando interferências ora indiretas, ora diretas nos momentos que estariam destinados para a ausência de trabalho.

Estamos denominando de estado de "pré-atenção induzida", ou seja, um estado de alerta em que o(a) intelectual permanece 
por ter clareza de que tarefas podem lhe ser solicitadas a qualquer momento, isto é, um fenômeno social decorrente dessas interferências indiretas a que esses trabalhadores(as) estão expostos(as) em tempo integral. Com relação às interrupções diretas do trabalho no tempo destinado ao não trabalho, isto é, as solicitações de tarefas que Ihes chegam por meio de comunicados por suportes tecnológicos, como os e-mails, Facebook e WhatsApp, temos um importante aspecto a ser analisado: o redimensionamento das características do tipo de atenção exigida desses intelectuais para a execução dessas tarefas solicitadas por meio de interferências diretas no tempo destinado ao não-trabalho, causadores da intensificação do trabalho e, com esta, a possibilidade de adoecimento desses docentes.

Conceituamos esse estado direto de atenção para a execução de várias atividades que são solicitadas simultaneamente para os docentes universitários quando estão em seu "tempo stand by" como um estado de "hiperatenção fluida”. A hiperatenção fluida se caracteriza por um esforço de atenção duplicado que os docentes precisam desenvolver para executar diferentes atividades que exigem muita atenção. Para tal, ao mesmo tempo em que os docentes necessitam estar em um estado de hiperatenção, eles se encontram em um estado de fluidez para conseguir atender às diferentes demandas trabalhistas que Ihes chegam via online em tempo integral. O "tempo stand by" é a imposição de um estado permanente de excesso de atenção no trabalho.

Nesse sentido, o "tempo stand by" é constituído por um tempo integral de disponibilidade dos docentes, no qual a atenção oscila entre uma intervenção indireta do trabalho, que tem como causa um estado de "pré-atenção induzida" com várias e simultâneas intervenções diretas do trabalho, e que possui como decorrência um estado de "hiperatenção fluida". Estamos, portanto, diante de uma ética do trabalho que se organiza tendo a fadiga mental desses trabalhadores(as) como um elemento constitutivo da sua ética. Nessa manifestação cultural própria dessa organização do trabalho, exige-se um estado de atenção que se intercala entre momentos de "pré-atenção induzida" e momentos de "hiperatenção fluida", que se estabelecem de modo ininterrupto. O imperativo que se manifesta não é por uma "distração concentrada", ou seja, não se trata de uma atenção que está concentrada na distração, mas, sim, em um estado em tempo integral de atenção concentrada de característica fluida. Trata-se da necessidade de um excesso de atenção constante para que o(a) intelectual consiga realizar uma demanda constantemente fluida de atividades que exigem muita atenção.

Problemas como a possibilidade de queda na qualidade dos trabalhos científicos desenvolvidos por esses(as) intelectuais, assim como de seu adoecimento, não advêm de uma organização de trabalho edificada em torno de uma "distração concentrada" produtora culturalmente de sujeitos com "déficit de atenção", mas sim, de uma organização de trabalho que exige desses profissionais um estado ininterrupto de atenção que oscila entre momentos de "pré-atenção induzida" e de "hiperatenção fluida".

Nesse sentido, tanto o fenômeno social da "distração concentrada" e da edificação de uma cultura do "déficit de atenção" desenvolvido por Türcke (2010), como o excesso de atenção advindos do que estamos denominando de "intervenções indiretas" (pré-atenção induzida) e "intervenções diretas" (hiperatenção fluida) características do tempo standy by na organização social do trabaIho dos pesquisadores(as), tratam-se de tendências semiformativas que possui um elo: a percepção acelerada do tempo e a busca dos sujeitos pela integração social.

No caso específico dos docentes da carreira do magistério superior, a aceleração do tempo para que produzam conhecimento e a maneira semiformativa como essa produção é quantificada pelos processos de avaliação, sobretudo, dos programas de pós-graduação, configuram uma das principais características do processo de coisificação desses profissionais. 
A formação cultural do professor universitário não padece com a distração concentrada, mas com a aceleração induzida de processos cada vez mais intensificados de atenção. Essa aceleração do tempo é um vício estrutural que é alimentado e intensificado pelos suportes tecnológicos, como o e-mail, e que são estendidos também ao Facebook e ao próprio WhatsApp. A certeza da disponibilidade de acesso, quase que imediato, que tais aparatos tecnológicos asseguram às instituições, permite que as mesmas encurtem cada vez mais os prazos para a execução de atividades laborais que requerem muita atenção para serem executadas. Nesse sentido, a atenção precisa ser cada vez mais fluida para dar conta das inúmeras atribuições que são apresentadas a esses profissionais, ao mesmo tempo em que necessita ser mais intensa para que o mínimo de qualidade intelectual seja garantido nessas produções, em virtude de um processo de encurtamento de prazos cada vez mais intensificados como exigência para a finalização das mesmas.

Aquilo que em um primeiro momento pareceu um ganho para o(a) trabalhador(a), por exemplo, a possibilidade de executar trabalhos em sua própria casa, tornou-se uma espécie de droga da espoliação integral. Nesse vício estrutural, o docente para não ser tipificado como desqualificado e irresponsável necessita acessar os seus e-mails várias vezes no mesmo dia, responder mensagens inbox de imediato pelo Facebook e, inclusive pelo WhatsApp sobre trabalho. O trabalho, além de invadir sua casa, invade suas férias, os finais de semana, os feriados, enfim, os momentos que em princípio não estariam destinados ao trabalho. Esse ritmo frenético de impossibilidade ao direito de se desconectar como ética desse profissional, impõe a esses profissionais a incapacidade de parar de estar atento ao trabalho, cujo principal rival formativo dos docentes, encontra-se na aceleração da percepção do tempo.

O processo de coisificação desses docentes, com relação à sua produção de conhecimento, estabelece-se pela quantifica- ção dessa produção simbolizada no currículo Lattes desses profissionais. Na avaliação dos programas de pós-graduação, materializada na plataforma Sucupira, a lógica desse processo de coisificação pela via da quantificação é objetivada. Não interessa o processo formativo em que o docente esteve envolvido, por exemplo, para a publicação de um artigo, mas sim, a quantidade desses. Mencionamos a questão da publicação dos artigos que seria um critério, entre tantos outros, estabelecido por essa mesma lógica quantitativa. Os programas que mais se integram a essa lógica da coisificação são aqueles apresentados como detentores de maior qualidade, o que, nesta nossa reflexão sobre processos semiformativos, é questionável. Ao final do quadriênio CAPES (Coordenação de Aperfeiçoamento de Pessoal de Nível Superior), os docentes necessitam, por mecanismos quantitativos, avaliar os próprios pares - em uma espécie de processo de algoz vigília - para efetivarem os processos de credenciamento e descredenciamento dos seus colegas com a finalidade de enquadrar o programa aos requisitos exigidos para que o mesmo possa ser considerado de qualidade. Nessa ética do(a) intelectual online, tanto as características semiformativas do que denominamos de "tempo stand by", como as caraterísticas do que Adorno (1995) denominou de "tempo livre", são manifestadas.

Um exemplo de manifestação semiformativa - nos moldes do que Adorno (1995) denominou de "tempo livre" -, encontra-se em um fenômeno muito recorrente na internet e que estamos tipificando como uma espécie de extensão publicitária do Lattes, no qual descobrimos no Facebook um suporte para tal finalidade. Destacamos que, por meio do Facebook, esses(as) profissionais podem divulgar aos seus pares seus trabaIhos acadêmicos. Se, por um lado, esse suporte tecnológico interativo carrega em si a potência de trocas importantes de produções intelectuais, por outro lado, tal comportamento aproxima ideologicamente esses profissionais, 
[...] daqueles que se deixam queimar ao sol, só por amor ao bronzeado e, embora o estado de letargia a pleno sol não seja prazeroso de maneira nenhuma, e talvez desagradável fisicamente, o certo é que torna as pessoas espiritualmente inativas. O caráter fetichista da mercadoria se apodera, através do bronzeado da pele - que, de resto, pode ficar muito bem -, das pessoas em si; elas se transforam em fetiches de si mesmas. A idéia de que uma garota, graças à sua pele bronzeada, tenha um atrativo erótico especial, é provavelmente apenas uma racionalização. $O$ bronzeado tornou-se um fim em si, mais importante que o flerte para o qual talvez devesse servir em princípio. Quando um funcionário retorna das férias sem ter obtido a cor obrigatória, pode estar certo de que os colegas perguntarão mordazes: "Mas não estavas de férias?" O fetichismo que medra no tempo livre está sujeito a controles sociais suplementares. Que a indústria dos cosméticos, com sua propaganda avassaladora e inevitável, contribua para isso é tão natural e evidente quanto o é que as pessoas condescendentes o reprimam (ADORNO, 1995, p. 74-75).

O caráter fetichista da mercadoria também é intrínseco ao processo de publicidade e propaganda que os produtos culturais, como, a produção de conhecimento dos(as) intelectuais podem assumir na veiculação dos mesmos, por meio, por exemplo, do Facebook, com uma lógica muito próxima da mercadológica, quando o processo de divulgação da imagem desses(as) intelectuais, em inúmeras atividades acadêmicas, termina por causar um efeito de autoria em quem consome tais imagens. Exposto de outra forma, funciona como se a imagem constantemente divulgada desses(as) intelectuais já fosse as suas res- pectivas produções intelectuais, no qual a autoridade e o reconhecimento dos seus pares não se estabelecem necessariamente pela via da análise do que está sendo produzido por aquele intelectual, mas, sim, à medida que sua imagem é socializada como intelectual em determinada área do conhecimento, e inúmeras vezes percebida. Esse fenômeno, estamos aqui conceituando de (auto)imagem como autoria. Nesse sentido, os(as) intelectuais não se encontram isentos da luta pela sua existência, que somente é reconhecida na sociedade contemporânea como imagem percebida:

Ser significa ser percebido. Ser percebido não apenas pelo chefe da reunião, mas também a todo momento pelo diretor. As malas-diretas diárias testemunham isto não menos do que os manuscritos das montanhas, os quais se assemelham ainda mais a elas nas redações. Um timbre estranho, uma escrita excêntrica, a assinatura que já é conhecida; tais insignificâncias podem então ser decisivas no caso de um redator começar a ler um texto ou um chefe do departamento pessoal dirigir examinar, com o olhar mais apurado, uma solicitação qualquer. Aquilo que não se percebe se torna marginalizado. E isto é válido não apenas para o mercado de trabalho nacional. Áreas mundiais inteiras não são percebidas: a Nicarágua após a queda dos sandinistas, o Iraque após a guerra do golfo, o sul do Saara, o nordeste brasileiro, a maior parte da ex-URSS etc. Isolar-se da percepção pública significa quase ser entregue à ruína político-econômica. O sequestro do avião, o tornar-se refém, a greve de fome, enfim, todos estes acontecimentos lutam entre si na ânsia de receber a pecha do extraordinário que pode ser assim percebido e também vendido. A sórdida propaganda da 
Benethon, que chama a atenção para os curdos e para a condição desesperadora de seu povo, não tem muito que se esforçar para poder ser notada. Impressionar para sobreviver é aquilo que predomina em ambas as situações, pois tanto o genocídio dos povos como as empresas que são ávidas por lucro estão subordinadas a essa obrigação. Os grupos de protesto gostariam de expor a mais pura miséria sem qualquer tipo de cálculo, contudo, eles não podem abster-se de fazer propaganda desta mesma miséria. É a ordem econômica que os força a fazer esse tipo de publicidade; é essa mesma obrigação que revela a forma como a Teoria Crítica foi, recentemente, utilizada para fazer o abc da crítica da sociedade (TÜRCKE, 2004, p. 65).

Essa mesma lógica mercadológica - que de modo autoritário impõe a necessidade de ser percebido como sinônimo de existência -, também é parte constitutiva e semiformativa do trabalho do(a) intelectual online na produção de conhecimento na academia. O fenômeno da utilização do Facebook como extensão do currículo Lattes, na divulgação da (auto)imagem como autoria, pertence a uma das facetas de dois processos de coisificação da produção intelectual que estão intrinsecamente relacionados à necessidade de ser percebido: percepção essa que se dá, por um lado, por meio da quantificação de produção elencadas no currículo Lattes e, por outro lado, na quantificação de (auto)imagens divulgadas - ambos os processos que estão relacionados com a necessidade do(a) intelectual online garantir a sua sobrevivência entre os seus pares, em um falso processo de reconhecimento, como parte constitutiva de um processo de integração com a finalidade de não se tornar marginalizado.

O processo de fetichização de si mesmo por mecanismos de quantificação - sejam es- ses apresentados em números no Lattes, sejam produzidos na divulgação constante da (auto)imagem como autoria por suportes midiáticos - são estratégias de sobrevivência na academia, que terminam por fomentar uma espécie do que Adorno (2010) denominou de mentalidade do ticket, mas que estamos diagnosticando como sendo uma espécie de mentalidade do ticket às avessas:

O semiculto dedica-se à conservação de si mesmo sem si mesmo. Não pode permitir, então, o que, segundo a teoria burguesa, constituía a subjetividade: a experiência e o conceito. Assim procura subjetivamente a possibilidade da formação cultural, ao mesmo tempo em que, objetivamente, se coloca totalmente contra ela. A experiência - a continuidade da consciência em que perdura o ainda não existente e em que o exercício e a associação fundamentam uma tradição no indivíduo - fica substituída por um estado informativo pontual, desconectado, intercambiável e efêmero, e que se sabe que ficará borrado no próximo instante por outras informações. Em lugar do temps durée, conexão de um viver em si relativamente uníssono que desemboca no julgamento, coloca-se um “É assim” sem julgamento, algo parecido à fala dos viajantes que, do trem, dão nomes a todos os lugares pelos quais passam como um raio, a fábrica de rodas ou de cimento, o novo quartel; sempre prontos para dar respostas inconsequentes a qualquer pergunta. A semiformação é uma fraqueza em relação ao tempo [...], à memória, única mediação capaz de fazer na consciência aquela síntese da experiência que caracterizou a formação cultural em outros tempos. Não é por acaso que 
o semiculto faz alarde de sua má memória, orgulhoso de suas múltiplas ocupações e da consequente sobrecarga (ADORNO, 2010, p. 33).

Nesses dois processos de coisificação já mencionados, a ética do(a) intelectual online está em comunhão com a ética da integração da sociedade globalizada. Esses processos colaboram para o que estamos denominando de "mentalidade do ticket às avessas", e que explicamos: se em Adorno a "mentalidade do ticket" auxilia na veiculação de estereótipos que podem reforçar uma situação social de preconceito e de consequente exclusão, no caso por nós analisado, esses intelectuais, justamente por esse processo de estereotipia do que é ser um(a) intelectual nos moldes quantitativos já elencados, desenvolvem o que estamos denominando de "mentalidade do ticket às avessas" que favorece a integração e não a exclusão. Isso se manifesta porque esses estereótipos, muitas vezes, terminam por desenvolver um preconceito com base em dados quantitati- vos, que auxiliam na conquista da integração dentro do meio acadêmico. Trata-se, portanto, do desenvolvimento de rótulos pontuais e superficiais que não marginaliza os sujeitos sujeitados, ou seja, da produção de uma espécie de preconceito integrativo e, portanto, às avessas. $\mathrm{O}$ marginalizado é o próprio processo formativo.

Nesse processo semiformativo de integração, nós intelectuais online, trabalhamos muito, com jornadas de trabalho ininterruptas que exigem um dispêndio gigantesco de atenção para nos sentirmos orgulhosos dos números produtivos que nos coisificam, para nos tornarmos precisamente a antítese do que almejamos - ser um(a) intelectual emancipado. Nesse sentido, este ensaio, ao mesmo tempo em que denuncia objetivando uma resistência a esse estado semiformativo fundamentado em uma ética da integração a que passam nós intelectuais, ele é também a materialização de uma demanda empírica de trabalho desse mesmo processo. Enfim, neste ensaio, tratamos de reticências verídicas do pensamento, agora, elucidadas.

\section{REFERÊNCIAS}

ADORNO, T. W. "Teoria da Semiformação." In: PUCCI, B; RAMOS-DE-OLIVEIRA, N.; ZUIN, A. A. S. (Orgs.). Teoria crítica e inconformismo: novas perspectivas de pesquisa. Campinas: Autores Associados, 2010.

. Tempo livre: palavras e sinais modelos críticos 2. Petrópolis: Vozes, 1995.

BBC BRASIL. "Franceses ganham direito a 'folga de e-mail' fora do horário de trabalho", 2 jan. 2017. Disponível em: <http://www.bbc.com/portuguese/internacional-38471356>. Acesso em: 18 mar. 2017.

CARLOTTO, S. M. "A síndrome de Burnout e o trabalho docente." Psicologia em Estudo. Maringá, v. 7, n. 1, p. 21-29, jan./jun. 2002. Disponível em: <http://scielo.br/pdf/pe/v7n1/v7n1a03.pdf>. Acesso em: 18 mar. 2017.

EURONEWS. França introduz direito de ignorar e-mails fora do trabalho, 2. jan. 2017. Disponível em: <http://pt.euronews.com/2017/01/02/franca-introduz-direito-de-ignorar-emails-fora-do-trabalho>. Acesso em: 18 mar. 2017.

GIACOIA JUNIOR, O. "A ética na era da globalização à luz do pensamento de Adorno." In: ZUIN, A. A. S.; BELARMINO C. G.; PUCCI, B. (Orgs.). Teoria crítica, ética e educação. Campinas: Editores Autores Associados 2001.

LEVY, P. O que é o virtual. São Paulo: Editora 34, 1996.

. Cibercultura. São Paulo: Editora 34, 1999.

MARCUSE, H. A ideologia da sociedade industrial: o homem unidimensional. Rio de Janeiro: Zahar, 1973.

RAMOS-DE-OLIVEIRA, N. "A ironia como ato de desvelamento." In: PUCCI, B.; RAMOS-DE-OLIVEIRA, N.; ZUIN, A. A. S. (Orgs.). Ensaios Frankfurtianos. São Paulo: Cortez, 2004. 
SENNETT, R. A corrosão do caráter. Rio de Janeiro: Record, 2011. . "Sociedade da sensação: a estetização da luta pela existência." In: PUCCI, B.; RAMOS-

-DE-OLIVEIRA, N.; ZUIN, A. A. S. (Orgs.). Ensaios Frankfurtianos. São Paulo: Cortez, 2004.

TÜRCKE, C. Sociedade excitada: filosofia da sensação. Campinas: Editora da Unicamp, 2010.

\section{DADOS DA AUTORA}

Doutora em Educação pela Universidade Estadual Paulista (UNESP/FCLAr).

Docente Permanente do Programa de Pós-graduação em Educação da Universidade Federal de Mato Grosso do Sul (UFMS/CPAN). Corumbá/MS.

Docente Colaborador do Programa de Pós-graduação em Educação da Universidade Federal de Mato Grosso do Sul (UFMS/FAED). Campo Grande/MS.

bella.fernandaferreira@gmail.com

Submetido em: 14-4-2017

Aceito em: 12-7-2017 